\title{
La vida de la venerable María de Jesús Tomellín. Origen y destino de una vida libresca
}

\section{The Life of the Venerable María de Jesús Tomellín. The Origin and the Destination of a Bookish Life}

Nayeli Marisol Crespo García [nayeli.m.crespo@gmail.com]

Universidad Nacional Autónoma de México, México

\section{RESUMEN}

El presente artículo, más que enfocarse en el camino de un libro físico, pretende hacer un recorrido textual sobre la vida libresca de una monja poblana que murió en 1637 con fama pública de santidad y a quien sus contemporáneos y fieles intentaron canonizar en diversas ocasiones por distintos medios, uno de ellos, quizás el más fecundo, fue a través de biografías escritas o publicadas tanto en la Nueva España, como en la Península Ibérica e Italia. Me refiero a María Tomellín del Campo, mejor conocida por su nombre monjil: sor María de Jesús o su mote popular: el Lirio de Puebla.

\section{Palabras Clave}

Vida de monja; biografía; sor María de Jesús; intertextualidad

\begin{abstract}
The present article does not focus on a route of a physical book but aims to realize a textual journey about a bookish life of one nun from Puebla who died in 1637 with public fame of sanity and whom her contemporaries and believers strived to canonize in various occasions and by different ways. One of those means, maybe the most fertile one, was through biographies written or published in New Spain as well as in the Iberian Peninsula and in Italy. I am speaking about María Tomellín del Campo, better known for her nun name: María de Jesús or her popular nickname: the Lily of Puebla.
\end{abstract}

\section{KEYWORDS}

Nun’s life; biography; nun María de Jesús; intertextuality

RECIBIDO 2018-04-13; ACEPTADO 2018-06-05 
Cuando un libro llega a nuestras manos, podemos afirmar que han sido muchos los caminos por los que ha peregrinado para hacerlo, y si ese libro es una obra del virreinato novohispano, suponemos que ese trayecto nos lleva siglos de ventaja. Podría pensarse que el vertiginoso viaje que hacen los libros comienza al salir de la imprenta; sin embargo, este empieza mucho antes y en ocasiones los autores dejan pistas a sus lectores para poder conocerlo y desentrañarlo.

Nuestro recorrido comienza con la descripción y características del género al que pertenecen las Vidas, y procede con los antecedentes bibliográficos que otorga el bachiller Francisco Pardo en su "Prólogo al lector" en la Vida y virtudes heroicas de la madre María de Jesús: ¿quiénes escribieron o pretendieron hacerlo antes que él?, ¿cómo fue ese camino para otros biógrafos? Finalmente concluye con un breve recuento de las biografías que sucedieron a la de Pardo.

\section{El género}

Las llamadas Vidas de monjas distan mucho de la biografía contemporánea, ya que seguían la estructura y los patrones de la hagiografía, por lo que la narración no obedece en sentido estricto a lo que aconteció en el plano real (aunque éste siempre es su base), sino que se ajusta a un modelo literario que estaba perfectamente delimitado desde la Edad Media y que continuó vigente hasta bien entrado el siglo XIX; de tal suerte que en la hagiografía se cuentan acciones y sucesos específicos del protagonista en un orden más o menos delimitado para demostrar su predestinación a la santidad, y tanto las hagiografías como las Vidas de monjas tienen características afines:

a] un desarrollo del tiempo lineal desde el nacimiento hasta la muerte; b] la mención del origen del biografiado; c] el inicio de sus rasgos excepcionales en su seguimiento puntual de las virtudes; d] la repugnancia hacia el vicio; e] pruebas puestas por Dios para desarrollar el camino de perfección; f] voluntad a toda prueba; y g] el recuerdo indeleble de su memoria después de la muerte. (Bravo 2010: 312)

Fernando Baños ha dicho sobre la hagiografía que ésta no es otra cosa que una biografía, pero que verla así da como resultado una visión incompleta de la misma. Señala que las primeras manifestaciones hagiográficas surgieron al margen de la biografía clásica pagana, y tuvieron su origen en las relaciones de los procesos y las ejecuciones de los mártires de los inicios del cristianismo, por ello se acercan más al modelo de las Vidas paralelas de Plutarco, texto que se estructura en orden cronológico (Baños 2003: 63-64). En la obra, Plutarco compara la vida de dos hombres ilustres, uno griego y otro romano, que se relacionan por alguna afinidad de carácter o por sucesos similares de sus vidas. La estructura de cada una de las vidas es más o menos la siguiente: El autor anota el linaje del personaje y su lugar de nacimiento; describe tanto sus características físicas como morales, para dar cuenta de estas últimas, introduce pasajes en los que se refleja el temperamento de los protagonistas, los cuales se caracterizan por medio de sus acciones, sus integridades y sus defectos. Finalmente registra su descendencia. 
Cuando se leían las vidas de personas que aún no llegaban a ser santas de forma oficial, pero que eran aclamados como tales, el efecto en el receptor debía ser el mismo que si de santos verdaderos se tratara. Jerónimo de Mendieta dice sobre estas Vitae:

De tres cosas nos hemos de acordar en las vidas de los santos: la primera es del buen ejemplo que nos dieron con su vida mientras vivieron en el mundo. La segunda, de cotejar nuestra vida con la suya para nuestra confusión [es decir, para nuestra vergüenza]. La tercera, de cómo nos favorecen agora delante de Nuestro Señor Dios en la gloria. (Medieta, apud Bravo 2010: 312)

Casos como el de la madre María de Jesús, o de tantas otras monjas merecedoras de ser perpetuadas en la mente de los novohispanos, tenían la ventaja de que sus historias eran más cercanas a los lectores de este lado del Atlántico, tanto en el tiempo como en el espacio. La concepcionista, al ser considerada prácticamente santa, se convirtió en el orgullo de los poblanos. Un medio propicio para plasmar este sentimiento fue la literatura edificante, en la que los textos sobre religiosas no sólo describían a las mujeres como paradigmas de virtud y modelos de vida, además las convertían en símbolos de exaltación patriótica de un lugar determinado. Ellas promovían el orgullo y el arraigo a la ciudad natal entre los habitantes, pues naturalmente éstos se sentían más identificados con venerables lugareños, a quienes muchas veces habían conocido o cuyas historias habían escuchado desde pequeños en una especie de leyenda.

Dolores Bravo ha notado que los textos hagiográficos despertaban en sus lectores una catarsis devocional y estética, al hacer suyas las aventuras de los protagonistas de santidad, ya que "la identificación que se estableció entre héroe y lector es equiparable a la catarsis que se ha venido dando desde los lectores u oyentes griegos y que consagra al héroe como icono modélico a lo largo de los siglos" (Bravo 2010: 312). Pero el sentimiento de simpatía y empatía que los protagonistas hagiográficos producían en sus receptores iba más allá de eso: el gran poder del santo era interceder por sus devotos ante Dios, con ellos los seres humanos podían entablar vínculos más estrechos con la divinidad. Esto es de suma importancia: si los santos son capaces de interceder por los hombres ante Dios, también se pueden convertir en elementos de cohesión para una comunidad, en la medida en que se vuelven merecedores de devoción y de culto.

Los novohispanos, al estar en una búsqueda constante de elementos que construyeran su identidad, hallaron una pieza fundamental para constituir su ser criollo en los favores que Dios había derramado sobre su tierra, y una de las maneras más efectivas que encontraron para hacerlo fue la promoción de los santos:

la existencia de personas santas nacidas o relacionadas con la Nueva España demostraba la igualdad entre los novohispanos y los europeos, y daba a conocer que su tierra tenía la suficiente madurez espiritual, que su cristiandad era un espejo de modelo apostólico de la Iglesia de los primeros tiempos. (Rubial 2001: 341)

Así fue como la Nueva España se convirtió en un lugar ávido de santos propios. Una de las mejores formas de reconocer, formalizar y difundir la santidad fue por medio de la hagiografía; y pese a que no podemos afirmar que las Vidas escritas sobre estos aspirantes a la santidad sean en sentido estricto hagiografías — pues ninguno de ellos llegó a los altares, y el vocablo se 
refiere sólo a las Vitae sanctorum-, sí podemos aseverar que su estructura corresponde a este género.

Uno de los personajes que dio origen a más escritos sobre su vida fue la venerable María de Jesús. Sus diversos biógrafos deseaban contribuir en el proceso de canonización de la monja y lograr que la Vida que ellos escribieron se convirtiera en la hagiografía oficial sobre la religiosa, por lo que todos siguieron el modelo hagiográfico.

\section{Las Vidas de María de Jesús}

Las Vidas de monjas eran parte de un proceso de escritura complejo. Las mujeres que se dedicaban a la vida conventual y sobresalían del resto de sus hermanas de hábito solían proporcionar la materia prima de escritura de sus biografías, pero fueron pocos los casos de aquellas que escribieron sus propias historias sin que interviniera la mano de una segunda persona, por lo general la de su confesor, quien se apropiaba del discurso de la religiosa, lo reinterpretaba y lo reelaboraba de acuerdo con la estética y los cánones de la época. Éste es un proceso que ha ocurrido desde hace siglos: un autor culto y con autoridad se vale de los documentos producidos por un personaje marginal y subordinado, al que se le resta importancia y cuya voz se diluye en el escrito, aunque, paradójicamente, esta voz es la fuente principal de la obra.

Las biografías que se conocen sobre María Tomellín del Campo fueron un caso aún más complejo, pues fueron múltiples manos y voces las que se encargaron de transmitir su vida; lo que se debió al ferviente deseo de los poblanos por canonizarla, ya que aseguraban que: "Fue elegida su virtud, por el mismo Dios, en el cargo tutelar y abogada de la Puebla para que no descargase la divina justicia el azote en orden a castigar o a destruir la ciudad de los Ángeles" (Pardo 1676: t. I, 41).

En 1661, veinticuatro años después de la muerte de sor María de Jesús, el obispo poblano Diego de Osorio intentó iniciar el proceso de canonización de la monja. La postulación fue rotundamente rechazada, pero el obispo no se dio por vencido y en 1672, un año antes de su muerte, volvió a intentarlo; esta vez con un resultado favorable, el cual se vio reflejado en 1684, cuando la Santa Congregación de Ritos abrió la causa y la monja obtuvo el grado de sierva de Dios. Más tarde, en 1695, Manuel Fernández de Santa Cruz retomó la causa, pero ni su intento ni los posteriores rendirían los frutos esperados, pues el caso de sor María no avanzó más y el proceso, como muchos otros en la Nueva España, quedó congelado ${ }^{1}$.

Para comenzar el proceso de canonización, Diego de Osorio mandó a escribir la Vida y virtvdes heroycas de la Madre MARÍA de JESVS, y encomendó la empresa a Francisco Pardo, quien publicó la biografía en 1676. Pero ellos no fueron los primeros que desearon e intentaron efectuar la canonización de sor María. En el prólogo, el bachiller relata al lector quiénes se aventuraron a escribir antes que él, así como las peripecias que atravesaron. "Sujetos grandes", "personas ilustres", "estilos elocuentes" y "aventajados oradores" (Pardo 1676: s/f) fueron a quienes se les encomendó la tarea de escribir la vida de sor María de Jesús, mas ninguno de ellos tuvo éxito, ya que, señala Pardo, Dios "quería por entonces suspender el concurso para proceder a esta obra" 
(Pardo 1676: s/f). ¿Por qué? El bachiller no lo dice en un inicio, pero un lector avezado puede darse cuenta de que a lo largo de las anécdotas sobre los intentos fallidos de escribir la biografía de la monja, Pardo se va construyendo a sí mismo como un elegido de Dios para llevar a cabo este encargo. El inicio del prólogo es muy revelador:

Reserva la sabiduría eterna para ciertos y determinados tiempos, o más oportunas ocasiones, la noticia de algunos primores suyos y esmeros singulares de su soberano poder; dando a cada uno de los siglos los realces que conviene con la execución de las obras magníficas, que su idea superior vio y previno desde la eternidad y sacó a luz cuando llegó a medirse con la conveniencia la coyuntura. (Pardo 1676: s/f)

La sabiduría que refiere Pardo es la divina, y lo que ésta tenía reservado para un tiempo mejor era el momento en el que debía escribirse la Vida de Tomellín del Campo, acto que, dice Pardo, el Altísimo tenía pensado desde el inicio de los tiempos. De manera que Dios reservó al bachiller la tarea de dar a la luz la vida de sor María de Jesús. Él mismo lo señala abiertamente al final de su prólogo:

Por inscrutable disposición de el Señor de todo lo criado, cuya designación benigníssima e infinita bondad, porque claramente se vea que es acción de toda su grandeza sola y magnificencia summa, la dessignó (no sin confusión vergonzosa mía) a la más torpe pluma, a la más tarda inteligencia, a la mayor y menos idónea ignorancia, que con minerva ruda, corto ingenio, balbuciente narrativa, escrive lo que no llegó a entender y publica lo que no alcançó a rayar, obligado a las repetidas instancias de algunas personas. (Pardo 1676: s/f)

Desde una postura de humilitas autorial, en la que Pardo se muestra sorprendido de la selección que hizo Dios al elegirlo como biógrafo de sor María, se señala como un escritor torpe, sin mucha inteligencia, de pluma ruda... Sin embargo, él es el elegido, y ese, en la cultura cristiana es el mayor de los elogios. Para que el lector pudiera darse cuenta de esto, el biógrafo se encargó de narrar previamente el recorrido infortunado que tuvo la biografía antes de que él la compusiera.

Primero Juan de Palafox y Mendoza encargó al jesuita Juan Eusebio Nieremberg escribir la biografía de sor María de Jesús:

... Don Juan de Palafox y Mendoza, Obispo de esta Diocessis de los Ángeles, [...] solicitó a aqueste insigne Prelado que escriviesse con más latitud el Assumpto presente [la vida de sor María] a aquel Historiador grande en el espíritu y en el estilo, el P. Juan Eusebio Nieremberg. (Pardo 1676: s/f)

Posteriormente a fray Juan de Jesús María, el Dr. Agustín de Pereda y el presbítero Pedro de Suárez, todos confesores de la madre María, se les encomendó la empresa, pero o no pudieron comenzar o se vieron impedidos a continuar su labor por extraños designios de Dios. Poco después el mismo Francisco de Florencia estuvo interesado en escribir los elogios de la monja, así como otros jesuitas: Juan de san Miguel y Matías de Bocanegra. Los dos primeros no 
consiguieron los documentos necesarios para emprender esta tarea y el último adoleció de males tan grandes que "aunque se había obligado con voto a hacer el tratado y descripción de esta vida, siempre le impidieron la ejecución de estos designios continuos males y debilidades indefectibles" (Pardo 1676: s/f). Ninguno de ellos logró su cometido a pesar de que eran hombres de gran sabiduría. Fue, por el contrario, como diría Pardo, "una pobrecita iletrada y humilde religiosa”(Pardo 1676: s/f) la que más logró escribir sobre la madre María de Jesús: sor Agustina de santa Teresa, compañera de celda y confidente de la religiosa, quien "acavó de escribir vn compendioso tratado de la vida y virtudes de este ángel en carne” (Pardo 1676: s/f).

A pesar de que Pardo dio un papel secundario a la madre Agustina, sus informes fueron tan importantes que cuando Juan de Palafox pidió a Eusebio Nieremberg que escribiera la biografía de la monja, solicitó este breve libro, "mas también se frustró este intento, y malogrò esta dicha: o por la muerte de el señor don Juan, o por inscrutable [sic] disposición de el Señor" (Pardo 1676: s/f).

Sor Agustina fue consciente de la importancia de escribir la vida de sor María de Jesús, no sólo porque ella misma creyó en su santidad, sino porque, de alguna manera, se inmortalizó así misma en la biografía que escribió, no como autora, pero sí como un personaje de gran relevancia. La madre Agustina aparece desde el Tratado III y se va caracterizando poco a poco como la fiel e inseparable confidente de María de Jesús, a quien acompañó hasta el día de su muerte. Su tratado fue, de manera directa o indirecta, la principal fuente de la que Pardo nutrió su obra, porque a partir de lo que la monja escribió, el jesuita Miguel Godínez, confesor de ambas religiosas, redactó unos Apuntes de la vida de la Madre María de Jesús, texto del que el bachiller se sirvió copiosamente.

En 1683 Diego de Lemus utilizó los mismos documentos de los que se valió Francisco Pardo y, muy probablemente, de la biografía escrita por el bachiller, aunque no le da crédito. El peninsular sólo dice que alguien le dio un texto impreso, pero jamás dice de quién era:

Estando con este afecto [con la noticia de la vida de sor María], concurrí con una persona de grande autoridad, letras y exemplo, que advirtiendo en mí el deseo de adquirir más copiosas relaciones de sus acciones, me manifestó un libro impresso de su vida, unos manuescritos, de la madre Agustina de santa Teresa y otro del padre Miguel Godínez, de la compañía de Jesús, que trataban del mismo asumpto. (Lemus 1683: s/f)

Josefina Muriel señaló que a la obra de sor Agustina "entraron a saco todos, desde el primer biógrafo, Francisco Pardo, hasta Félix de Jesús María, sin darle más valor que el de una fuente de información, pero sin ocurrírseles publicarla" (Muriel 2000: 331). Un aspecto interesante del legado que dejó sor Agustina es que se dio bajo circunstancias atípicas. Lo usual en la época era que los confesores que observaban arrebatos místicos en sus hijas espirituales, les ordenaran poner por escrito sus experiencias, todas escribían "bajo el signo de la santa obediencia. $\mathrm{Da}[\mathrm{ba}] \mathrm{n}$ cuenta de una vida llena de temores y esperanzas, dudas y vacilaciones frecuentes, e informa[ba]n sobre sus experiencias con el Demonio, de lo sobrenatural, sus visiones y éxtasis" (Herpoel 1988: 50).

Y a pesar de que las monjas debían obedecer y escribir cuando sus superiores se lo ordenaran, era una tarea que no siempre querían hacer; Jean Franco ha notado que las monjas "se 
mostraban renuentes a reproducir en una prosa laboriosa lo que para ellas habían sido sublimes escapes de su cuerpo" (Franco 1994: 29). Lo extraño del caso de la madre Agustina es que sin ser ella la que padeció las experiencias místicas, se dedicó a escribir en una suerte de diario todo lo que le ocurría a su correligionaria.

Cuando la comunidad del convento de la Inmaculada Concepción presenció el portento de ver volar una hostia a la boca de sor María, Diego Romano y Govea, el en ese entonces obispo de Puebla, ordenó que alguien vigilara cuidadosamente a la monja. El vicario Antonio Cervantes Carvajal decidió que sería sor Agustina de santa Teresa, en una suerte de espía, quien redactaría a escondidas todo lo que hiciera la madre María de Jesús; y el padre Miguel Godínez fue quien la instruyó en cómo debía hacerlo. La tarea fue sumamente complicada. Pardo cuenta que el Diablo, que no descansa, se oponía constantemente a ello y ponía uno tras otro obstáculos:

la propia sagrada mitra [Diego Romano], que poco antes había mandado piadosamente se escriviesse la vida de la referida sierva de Dios, moviéndole siniestros informes y emulaciones perversas, [...] quiso quemar los papeles que hasta allí se avían trabajado y dispuesto; pero de todo triumphó la virtud, venciendo la verdad al engaño, la luz al horror, la vida a la muerte y el cielo al abismo. (Pardo 1676: s/f)

El bachiller no podía explicarse por qué una persona como Diego Romano pediría que se escribiera la vida de sor María y después se dejara seducir por chismes del convento e intentara quemar todo lo que se había escrito hasta el momento, de ahí que lo achaque al demonio. Además es todo un tópico que el demonio trate de obstruir a los que combatirán en su contra. Teológicamente, la confrontación entre el protagonista hagiográfico y el Diablo representa el eterno conflicto entre el Bien y el Mal; además funciona como prueba de santidad, ya que sólo los santos eran capaces de enfrentarse al Demonio y vencerlo. Literariamente, esta confrontación es muy atractiva y efectiva, ya que da dramatismo a los textos.

La madre Agustina de santa Teresa fue la primera a la que el Demonio acosó, "no le faltaron persecuciones de este compendio, contrapuestas astucias y nocturnos horrores de la región de las llamas, que pretendían oscurecer la verdad" (Pardo 1676: s/f). A veces la confundía tanto que cuando escribía temía hacerlo de forma incorrecta, y llegaba el momento en el que ya no podía continuar con su tarea; "antes, en lo poco que hasta allí se había ocupado, iba descubriendo erratas tan enormes y desaciertos tan extraños, que se determinó a romper dos o tres hojas" (Pardo 1676: s/f). Es evidente el proceso de autocensura en las líneas citadas, y quizás también una dosis de simple inseguridad en sus propias capacidades. Sor Agustina sabía perfectamente que si anotaba algo que el confesor u otros superiores consideraran herético, podía meter en serios problemas a su hermana de hábito. Sobre esto, Consolación Baranda señala:

Hay un episodio que se repite en varias biografías de monjas con fama de santidad, muy revelador del grado de interiorización de la censura: la destrucción de los propios escritos [...]. En unos casos se hace en cumplimiento de una orden del confesor que pone a prueba la obediencia y humildad de la escritora; otras veces es por iniciativa propia, debido al temor o las pesquisas inquisitoriales, pues sabían que los libros de materia religiosa eran doblemente suspectos. (Baranda 2013: 166) 
Hay que tener presente que en aquellos siglos, algunas experiencias de tipo sobrenatural -bilocaciones, arrobos, visiones, etc.- solían atribuirse ya a las mujeres místicas, ya a las alumbradas, ya a las herejes, ya a las brujas. Tanto unas como otras eran consideradas de humor melancólico, y se pensaba que esto las hacía propensas a ser tentadas por el mal: "los melancólicos eran especialmente proclives a que su mente fuera poseída por el Demonio, y los místicos, pues, propensos a la melancolía, en sus periodos de tristeza, enfrentaban el asedio del Diablo" (Millar 2011: 341).

Lo anterior hacía que estas mujeres fueran vistas como un peligro potencial para la sociedad. En caso de que no se ajustaran a las normas, se consideraba que debían ser castigadas ${ }^{2}$. Además, cabe destacar que hubo innumerables casos de ilusas que vivieron del siglo XVI al XVIII en España, y sobre todo en el Nuevo Mundo. Un claro ejemplo es el de "la beata embaucadora" María Lucía Celis, que afirmaba tener raptos místicos, y que se encontraba dentro de un grupo de "iluminadas", las cuales contaban sus vivencias al padre español Antonio Rodríguez Colodrero. Cuando fueron descubiertos por el Tribunal de la Inquisición, María Celis fue condenada a servir en el Hospital de San Lorenzo, y el padre Rodríguez fue deportado a su patria (Peña 2000: $\mathrm{s} / \mathrm{p}$ ).

La propia sor María de Jesús fue considerada ilusa en algún momento: "El mismo prelado y actual obispo, engañado por los chismes que oía, de las oposiciones que tenía dentro de los claustros de su convento, llegó a persuadirse y hazer concepto tenaz que la Madre MARÍA de JESVS era una muger ilusa y embustera" (Pardo 1676: t. II, 84).

Las monjas que escribían por mandato sabían que eran blanco de la crítica masculina, de ahí que lo hicieran siguiendo estrategias defensivas y cuidando muy bien lo que decían. Posteriormente, una vez que corregían u omitían desde palabras hasta anécdotas que creían que podían utilizarse en su contra; una segunda y hasta tercera mano, escudriñaba el documento y reprobaba lo que le parecía que iba en contra de la fe católica. Al respecto, Antonio Rubial observa:

En esta literatura dual, hecha de escritura y de vivencias, que se comparten, es difícil delimitar las aportaciones de cada una de las partes. La religiosa [...] hace entrega de una intimidad que ha sido alimentada por el mismo confesor; éste, que impone su forma de escritura y sus intereses, se ve sin embargo limitado por la experiencia que la monja, y sólo ella, ha vivido. (Rubial 2001: 169)

La apropiación de la voz de las monjas biografiadas era tal que incluso las citas que hacían sus biógrafos eran reelaboradas:

A menudo, las biografías redactadas por los varones abundan en textos entrecomillados. No son éstos palabras textuales de la monja biografiada, tomadas de sus propias confesiones. Se trata de notas que, en lugar de acreditarse a la verdadera autora, pasaban a formar parte de un discurso masculino culto, generalmente alambicado, saturado de retórica barroca, de citas de autores clásicos y de la Biblia, y firmado por el religioso en turno. De este modo, el documento autobiográfico propiamente dicho quedaba diluido. (Peña 1995: 13) 
En el caso de la Vida y virtudes heroycas de la Madre María de Jesvs, Francisco Pardo, al introducir la voz Tomellín del Campo o sor Agustina de santa Teresa, marca sus parlamentos con cursivas, pero es evidente que es una reelaboración del discurso de la madre Agustina, ya que el estilo de sus diálogos son iguales al resto de la obra.

Ahora podemos darnos cuenta del problema que enfrenta cualquier investigador que estudia biografías de monjas: en ellas suelen intervenir varias manos y varias voces. Los mismos escritos de sor Agustina, que iniciaron como informes secretos sobre su compañera, en muchas ocasiones fueron de autoría doble, pues la misma Tomellín del Campo solía dictar a su hermana de hábito lo que debía escribir.

Pardo cuenta que en una ocasión en la que sor Agustina destruía lo que había puesto sobre el papel, entró la madre María de Jesús a su celda. La cronista intentó ocultar lo que hacía pero Tomellín, que podía penetrar las mentes y las almas, le explicó que ya tenía noticia de la tarea que le habían encomendado, e intentó tranquilizarla diciéndole que no tenía por qué preocuparse. Sor Agustina, mortificada por el hecho de que se revelara el secreto, negó vehementemente lo que escuchaba, pero la venerable le dijo halagüeñamente:

no escrivas hermana por los puntos, que te señaló tu padre espiritual, sino por el estilo que Dios nuestro señor ha de darte a entender. [...] Hágote saber que nuestro señor me [h]a revelado, que tratas de escrivir mi miserable vida por orden de los superiores, que assí lo han mandado y dispuesto; y resignándome en lo que el Esposo celestial ordena acerca de esta inútil esclava suya, te diré (porque assí también me lo manda su Majestad Soberana) lo que en mí, indigníssima sierva suya, ha obrado sus eficazes milagros y inefables misericordias, más que mis flacas acciones, dándote parte de las mercedes que interior y exteriormente he recevido de su mano. (Pardo 1676: s/f)

En este pasaje se aprecia que, por un lado, en un despliegue de humildad sor María reconoce que no es digna de que Dios ponga sus ojos en ella; por el otro, que ha sido Él quien le ordenó dictar su vida a la madre Agustina. Para que no haya duda sobre la humildad de la monja, Pardo deja claro que ella considera significativa su vida no por lo que vale en sí misma ni por las acciones que realiza, sino por los milagros y las misericordias que Dios obró en ella. Es claro que sor María sabía lo que implicaba dejar testimonio de su existencia: dar a conocer los portentos de Dios en la tierra.

Por otra parte hay que tener presente la conciencia que tenían mujeres como sor María de Jesús sobre sí mismas como modelos de imitación. Sabían perfectamente que así como ellas habían seguido una o varias vidas ejemplares, de la misma manera podían convertirse en los nuevos paradigmas de cristiandad. Paradójicamente, sólo aquellas que intentaban con más ahínco aniquilar su ser terrenal, podían sobresalir del resto del grupo y lograr que los confesores pusieran los ojos en ellas ${ }^{3}$. El problema de esto, como ya lo he señalado, era que muchas veces no se sabía con exactitud si era Dios o el Demonio quien las obligaba a obrar, por lo que el Santo Oficio se dedicó a perseguir infatigablemente a las mujeres que, al ser ejemplo para los crédulos, ponían en riesgo no sólo sus almas, sino la ortodoxia católica. 
Otro aspecto, quizás más interesante, de la cita anterior es el hecho de que sor María instara a su compañera de celda a no seguir las indicaciones que le habían dado sus superiores para escribir. A pesar de que en el fragmento que nos presenta Pardo, María de Jesús se muestra con gran humildad y se califica a sí misma con adjetivos peyorativos, contrasta esa determinación que tiene de saltarse la autoridad del padre espiritual; en este caso nada más ni nada menos que el confesor de ambas monjas: el jesuita Miguel Godínez. Evidentemente, no podía hacer esto de forma tan abrupta, por eso al final se apresura a decir, de forma un tanto artificial: "todas nosotras [las monjas...] estamos sujetas a la obediencia de nuestro divino Esposo, y también a la de nuestro prelado, que sustituye sus vozes" (Pardo 1676: s/f), palabras que pudieron salir de la misma María de Jesús o que quizás Pardo añadió en un intento por suavizar el discurso de desacato que había referido de la monja previamente.

Aunque las religiosas se valían a menudo de la práctica de la autohumillación y hacían un voto de obediencia - por lo que debían respetar las órdenes de sus superiores de forma sumisa - en este párrafo sor María y sor Agustina dejan constancia de sus vidas como sujetos autónomos, así como la validación de su escritura, que, según palabras de Tomellín del Campo, emanaba de Dios. Además, en este punto las monjas tenían una gran ventaja sobre sus guías espirituales, ya que el conocimiento que poseían las místicas era inalcanzable para todos aquellos que no experimentaban los mismos raptos. Al respecto Jean Franco señala que durante el siglo XVII el misticismo fue aceptado como una forma de conocimiento para el que estaban especialmente dotadas las mujeres:

la experiencia mística no se adquiría por la erudición y no se captaba en el discurso. No había posibilidad de diálogo [...] de allí el problema de interpretación [...]. Aquí decenas de mujeres encontraban un poder que parecía trascender el de los mismos confesores y sacerdotes. (Franco 1994: 14)

Muchas veces el discurso de las religiosas oscilaba entre la sumisión y la rebeldía, y que ya fuera de forma velada o explícita:

Las religiosas reclaman una mayor atención por parte de las autoridades eclesiásticas y, al mismo tiempo, se reconocen tributarias de las mismas, sin que ello impida su crítica. En ocasiones se atreven a discrepar sutilmente con sus superiores. Las más audaces llegarán incluso a reivindicar abiertamente su derecho de expresión. (Herpoel 1988: 7)

Parece que este último es el caso de la sierva de Dios y de sor Agustina, quienes reconocen la valía de su escritura y se amparan en la premisa de que todo lo que dictara una y escribiera la otra sería inspirado directamente por Dios.

La tarea de Francisco Pardo fue tomar la información escrita tanto por Miguel Godínez en sus Apuntes de la vida de la Madre María de Jesús, como por el diario de Agustina de santa Teresa, y lograr demostrar a lo largo de su biografía que la vida de la madre María de Jesús no sólo era digna de imitación, sino que la hacía merecedora la santidad. Y con ello lograr abrir el proceso de canonización del Lirio de Puebla. Lo que no ocurrió. Después de eso, el proceso se congeló y todos los intentos fueron infructuosos para la causa, pero valiosos para la literatura y la historia. 
Siete años después de que Pardo escribió su obra, en 1683 se publicó la escrita por Andrés Sáenz de la Peña, intitulada Vida de la venerable María de Jesús, Angelopolitana religiosa, profesa de la Concepción de la Puebla de los ángeles ${ }^{4}$ y la de Diego de Lemus Vida, virtudes, trabajos, favores y milagros de la venerable madre sor María de Jesús; la primera publicada en Puebla de los Ángeles y la segunda en Lyon, Francia. En 1739, fray Giuseppe della Madre di Dio, publicó en Roma Storia de la vita, virtu, doni e grazie della venerabile serva de Dio sour Maria di Gesú, monca professa del venerabile monastero della Concezione de Angelopoli, nelle Indie Occidentali; en esta obra el autor agrega los milagros que sor María realizó en Italia. Finalmente en 1756, Félix de Jesús María publicó también en Roma, pero esta vez en español, Vida, virtudes y dones sobrenaturales de la venerable sierva de Dios sor María de Jesus.

Todos los libros que tenemos como legado sobre la vida de sor María de Jesús y los testimonios sobre aquellos libros que se perdieron o solamente quedaron en la imaginación de sus posibles escritores son una pequeña muestra de la importancia de las Vidas de monjas en el virreinato novohispano, principalmente en los siglos XVII y XVIII, cuando estos textos no sólo se veían como una fuente de verdad, que podían enseñar deleitando a la gente, sino también como un instrumento que ayudaba en los procesos de canonización.

Asimismo, las biografías sobre sor María evidencian el camino por el que solían pasar otros textos similares. Se contaba con textos base: en este caso uno redactado por una monja, los apuntes de la madre sor Agustina, otro redactado por su confesor, el de Miguel Godínez. Ambos documentos sirvieron como palimpsestos de biografías posteriores, que, a su vez, nutrieron las biografías posteriores, las cuales se iban ajustando cada vez más a las exigencias de la Santa Congregación de ritos, en un intento por que sor María de Jesús llegara a los altares, hecho que no sucedió, pero si sor María no fue una santa por decreto de la Iglesia católica, sí lo fue por la devoción popular.

\section{Referencias bibliográficas}

Andrade, V. de P. (1899). Ensayo bibliográfico mexicano del siglo XVII. México: Imprenta del Museo Nacional.

Baños, F. (2003). Las vidas de santos en la literatura medieval española. Madrid: Ediciones del Laberinto.

Baranda, C. (2013). La función de la censura en la configuración de la religiosidad femenina del siglo xvir. Una propuesta. In C. Esteve (Coord.), Las razones del censor. Control ideológico y censura de libros en la primera Edad Moderna (pp. 161-175). Barcelona: Universitat Autònoma de Barcelona.

Bravo, M. D. (2010). La hagiografía en el siglo XVIII. In N.Vogeley, \& M. Ramos Medina (Coords.), Historia de la literatura mexicana: desde sus orígenes hasta nuestros días. Cambios de reglas, mentalidades y recursos retóricos en la Nueva España del siglo XVIII (vol. 3) (pp. 308-338). México: Siglo XXI-UNAMFFyL (Lingüística y teoría literaria).

4 No he tenido acceso a la obra, pero Beristain de Souza da noticia de ella en la Biblioteca Hispanoamericana Septentrional, vol. II, p. 445; así como Andrade (1899: 519). 
Franco, J. (1994). Escritoras a pesar suyo: las monjas místicas del siglo XVII en México. Las conspiradoras. La representación de la mujer en México, versión actualizada (pp. 29-51). México: El Colegio de MéxicoFCE (Colección Tierra Firme).

Herpoel, S. (1988). «Al fin soi muger» Mujeres vistas por sí mismas. In M. Cruz García de Enterría, \& A. Cordón Mesa (Eds.), Actas del IV Congreso Internacional de la Asociación Internacional Siglo de Oro (AISO), edición a cargo de. T. I. (pp. 799-805). Alcalá de Henares: Universidad de Alcalá.

Jesús, F. (1756). Vida, virtudes y dones sobrenaturales de la venerable sierva de Dios sor María de Jesús, religiosa profesa en el V. monasterio de la Inmaculada Concepción de la Puebla de los Ángeles en las Indias Occidentales, sacada de los procesos formados para la causa de su beatificación y canonización. Roma: Imprenta de Joseph y Phelipe Rossi.

Lemus, D. (1683). Vida, virtudes, trabajos, favores y milagro de la venerable madre sor María de Jesús, angelopolitana religiosa del convento de la limpia Concepción de la ciudad de los Ángeles en la Nueva España y natural de ella. Lyon: Anisson y Posuel.

Millar, R. (2011). Narrativas hagiográficas y representaciones: el Demonio en los claustros del Perú virreinal. Siglo xvir. Historia (Santiago), 44, 2, (julio-diciembre), 329-367.

Muriel, J. (2000). Cultura femenina novohispana. México: UNAM.

Pardo, F. (1676). Vida y virtudes heroicas de la madre María de Jesús, religiosa profesa en el convento de la limpia Concepción de la Virgen María, nuestra señora en la ciudad de los Ángeles. México: Viuda de Bernardo Calderón.

Peña, M. (2000). Entre pecado y santidad. In La palabra amordazada, literatura censurada por la Inquisición. México: UNAM-FFyL.

_ (1995). Prólogo al Paraíso Occidental de Carlos de Sigüenza y Góngora. México: Conaculta (Cien de México).

- (2002). La crónica religiosa: Historia sagrada y conciencia colectiva. In R. Chang-Rodríguez (Ed.), \& B. Garza Cuarón (Coord.), Historia de la literatura mexicana: desde sus orígenes hasta nuestros días. La cultura letrada en la nueva España del siglo XVII (Vol. 2) (pp. 325-371). México: Siglo XXIUNAM-FFyL (Lingüística y teoría literaria).

- (2001). La santidad controvertida. Hagiografía y conciencia criolla alrededor de los venerables no canonizados de la Nueva España. México: FCE-UNAM-FFyL.

Rubial, A. (2001). La santidad controvertida. Hagiografía y conciencia criolla alrededor de los venerables no canonizados de Nueva España. México: Fondo de Cultura Económica / Facultad de Filosofía y Letras, UNAM. 